\title{
التحليل الجغرافي للمؤشرات الديموغرافية للتنمية في منطقة أبها الحضرية
}

\section{Geographical analysis of demographic indicators of development in a region Urban Abha}

$$
\text { دا جميلة عمر إبراهيم مدني }
$$

أستاذ مساعد (تخطيط إقليمي)، قسم الجغر افيا، كلية العلوم الإنسانية، جامعة الملك خالد، المملكة العربية السعودية

Email: gmila_omer@hotmail.com

\section{أ شادية سيف محمد القحطاني}

محاضر (جغر افية السكان)، قسم الجغر افيا، كلية العلوم الإنسانية، جامعة الملك خالد، المملكة العربية السعودية

ملخص:

إن العلاقة بين السكان و التنمية من الموضو عات التي اهتم بها المختصين في مجال الديمو غر افيا والاقتصاد ومتخذي القرار. و المؤشرات الديموغر افية هي نظام للبيانات الإحصائية المستخدمة في تحليل العمليات في المجتم. و على أساسها يمكن

الوصول الى نتائج حول عدد وبنية السكان الذين يعيشون في منطقة معينة. تحاول الدراسة التعرف على المؤشرات

الديمو غر افية للتنمية في منطقة أبها الحضرية ومدى ارتباطها بما تحقق من تتمية. وتظهر أهمية الدراسة في أن در اسة المؤشر ات الديموغر افية للتنمية توضح معدلات نمو السكان ومعدلات المو اليد والوفيات، والتي بدور ها ترتبط بتطور النظام الصحي ونو عية الخدمات التي تقدم للسكان.

تهدف الدر اسة إلى تحقيق الاتي: التعرف على معدلات نمو السكان في منطقة أبها الحضرية وتوضيح معدلات المو اليد السنوية في منطقة أبها الحضرية. ومعدلات الوفيات السنوية في منطقة أبها الحضرية و التعرف على نسبة صغار السن في منطقة أبها الحضرية. وتحاول الدر اسة التعرف على المؤشرات الديمو غر افية للتنمية في منطقة أبها الحضرية ومدى ارتباطها

بما تحقق من تتمية. ولتحقيق أهداف الدراسة تم استخدام المنهج الوصفي: لوصف الوضع الر اهن للمؤشرات الديمو غر افية للتنمية بمنطقة أبها الحضرية. و المنهج التحليلي الكمي: وتم استخدامه لقياس المؤشر ات الديمغر افية و أنثرها التنموي في منطقة أبها الحضرية وتوصلت الدر اسة الى إن معدل نمو السكان في المنطقة معقول، وان تطور الخدمات الصحية في المنطقة انعكس على تقليل معدل الوفيات بين الأطفال، كما انعكس على طول أمد الحياة بين السكان في المنطقة وان المنطقة شهدت

$$
\text { طفرة تنموية متوازنة مع حجم السكان. }
$$

كلمات مفتاحية: مؤشرات ديمو غر افية، أبها الحضرية، تتمبة 
المجلة الدولية لنشر البحوث والدراسات

International Journal of Research and Studies Publishing

ISSN: 2709-7064
المجلد الثاني - الإصدار الثامن عشر

تأريخ الإصدار: 20 أبريل 2021م

\title{
Geographical analysis of demographic indicators of development in a region Urban Abha
}

\begin{abstract}
The relationship between population and development is one of the topics of interest to specialists in the field of demography, economics and decision-makers. Demographic indicators are a system of statistical data used to analyze processes in society. On this basis, conclusions can be reached about the number and structure of the population living in a particular area. The study attempts to identify the demographic indicators of development in the urban area of Abha and the extent of their relevance to the development achieved. The importance of the study shows that the study of demographic indicators of development clarifies the rates of population growth and birth and death rates, which in turn are related to the development of the health .system and the quality of services provided to the population
\end{abstract}

The study aims to achieve the following: To identify the population growth rates in the urban area of Abha and to clarify the annual birth rates in the urban Abha region. And annual death rates in the urban area of Abha, and to identify the proportion of young people in the urban area of Abha. The study tries to identify the demographic indicators of development in the urban area of Abha and the extent of their relevance to the development achieved. To achieve the objectives of the study, the descriptive approach was used: to describe the current situation of demographic indicators of development in the urban Abha region. And the quantitative analytical approach: It was used to measure demographic indicators and their developmental impact in the urban area of Abha. The study concluded that the population growth rate in the region is reasonable, and that the development of health services in the region was reflected in reducing the mortality rate among children, as it was reflected in the longevity of life among the population in The region .and that the region witnessed a developmental boom balanced with the size of the population

Keywords: demographic indicators, urban Abha, development 
المجلة الدولية لنشر البحوث والدراسات

International Journal of Research and Studies Publishing
المجلد الثاني - الإصدار الثامن عشر تأريخ الإصدار: 20 أبريل 2021م

مقدمة:

تعتبر التنمية من العناصر الأساسية للاستقرار و التقدم الإنساني والاجتماعي، وهي عبارة عن عملية تقدم وتطور نحو

الأفضل تكون بشكل جزئي أو شامل باستمر ار تتفاوت بأثنكالها ، ونركز على تحقيق الرقي و التقدم في مجالات الحياة الإنسانية ، و المضي قدما بالإنسان نحو الاستقر ار المعيثي و الرفاهية، وتلبية متطلباته بما يتمانشى مع احتباجاته و إمكانياته في كافة المجالات الاقتصادية والاجتماعية .

إن العلاقة بين السكان و التنمية من الموضو عات التي اهتم بها المختصين في مجال الديمو غر افيا و الاقتصاد ومتخذي القرار. و أن تلبية الاحتياجات الأساسية للإنسان هي جزء هام من التنمية. في ظل هذا التحول إلى الأفضل ، يستطيع السكان زيادة الإنتاج وتحقيق المزيد من التنمية ، ومن هنا تأتي أهمية المؤشرات الديموغر افية ، ومن خلالها يمكن استنتاج بنية و عدد السكان الذين يعيشون في منطقة معينة وبالتالي يمكن التعرف على الحالة الصحية و الفرص الاقتصادية داخل هذا المجتمع. تثكل العوامل الديموغر افية الكثير من التحديات و الفرص المعقدة التي تو اجهها المجتمعات، و التي يرتبط عدد منها بالنمو الاقتصادي و التنمية، (بلوم،2020م، صوكر). مشكلة الدراسة: نتيجة الجهود المبذولة لأحداث التنمبة في كافة مناطق المملكة العربية السعودية، شهدت منطقة أبها الحضرية نهضة تتموية انعكست على جميع القطاعات فيها. تحاول الدر اسة التعرف على المؤشرات الديمو غر افية للتنمية في منطقة أبها الحضرية ومدى ارتباطها بما تحقق من تنمية. ومن ثم تحاول الدراسة الإجابة على التساؤلات التالية: 1/ ما معدل النمو السكاني في منطقة أبها الحضرية؟ /2 كم يبلغ معدل المو اليد في منطقة أبها الحضرية؟ 3/ كم يبلغ معدل الوفيات في منطقة أبها الحضرية؟ 4/ كم تبلغ نسبة صغار السن في منطقة أبها الحضرية؟ 5/ ما أثر المؤشرات الديموغر افية على مسار التنمية في منطقة أبها الحضرية؟

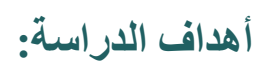
تهدف الدر اسة إلى تحقيق الاتي: 1/ التعرف على معدلات نمو السكان في منطقة أبها الحضرية. 
المجلة الدولية لنشر البحوث والدراسات

International Journal of Research and Studies Publishing

ISSN: 2709-7064
المجلد الثاني - الإصدار الثامن عشر

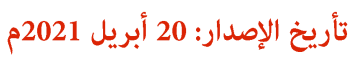

2/ توضيح معدلات المو البد السنوية في منطقة أبها الحضرية.

3/ توضيح معدلات الوفيات السنوية في منطقة أبها الحضرية

4/ التعرف على نسبة صغار السن في منطقة أبها الحضرية

أهمية الدراسة ومنهجيتها:

تعتبر در اسة المؤشر ات الديمو غر افية للتنمية مهمة لأنها توضح معدلات نمو السكان ومعدلات المو اليد والوفيات، والتي بدور ها ترتبط بنطور النظام الصحي و نوعية الخدمات التي تقدم للسكان، وتوزيعها الجغر افي ،وشرح و اقعها ، وتحقيق قدرِ كافِ منها ينعكس على الإنتاج و القدرة على العمل مما ينعكس ذللك على مستوى الدخل و المعيشة بالنسبة للسكان ، و الذي بدوره يوضح تطور المنطقة وتنميتها . لتحقيق أهداف الدر اسة تم استخدام المناهج التالية: 1/ المنهج الوصفي: لوصف الوضع الراهن للمؤشرات الديمو غر افية للتنمية بمنطقة أبها الحضرية. 3/ المنهج التحليلي الكمي: وتم استخدامه لقياس المؤشرات الديمغر افية وأثرها التنموي في منطقة أبها الحضرية

جغرافية منطقة أبها الحضرية:

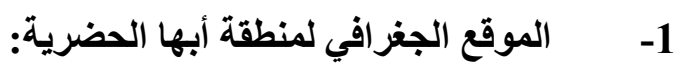
تقع منطقة أبها الحضرية بين دائرتي عرض ( 55 : 17 ، 33 : 18 ) وتتحصر بين خطى طول ( 9 : 42 ، 43 ) و تتنتمل منطقة أبها الحضرية على عدة مدن و هي:( أبها وخميس مثنيط واحد رفيدة ) وكذلك 341 تجمعا قرويا نتكل بمجملها منصلاً حضرياً متكاملاً .ويبلغ إجمالي مساحة المنطقة 1825 كم 2 ، كما يتضح من خريطة رقم ( 1) ، وترتفع منطقة أبها الحضرية 2270 متر فوق مستوى سطح البحر ـ لذا تتميز المنطقة باعتدال مناخها وبأعلى معدلات لهطول الأمطار في المملكة العربية السعودية لتعرضها لموسم الأمطار الموسمية الغزيرة. 
المجلة الدولية لنشر البحوث والدراسات

International Journal of Research and Studies Publishing

ISSN: 2709-7064
المجلد الثاني - الإصدار الثامن عشر تأريخ الإصدار: 20 أبريل 2021م

\section{خريطة رقم (1) موقع منطقة أبها الحضرية}

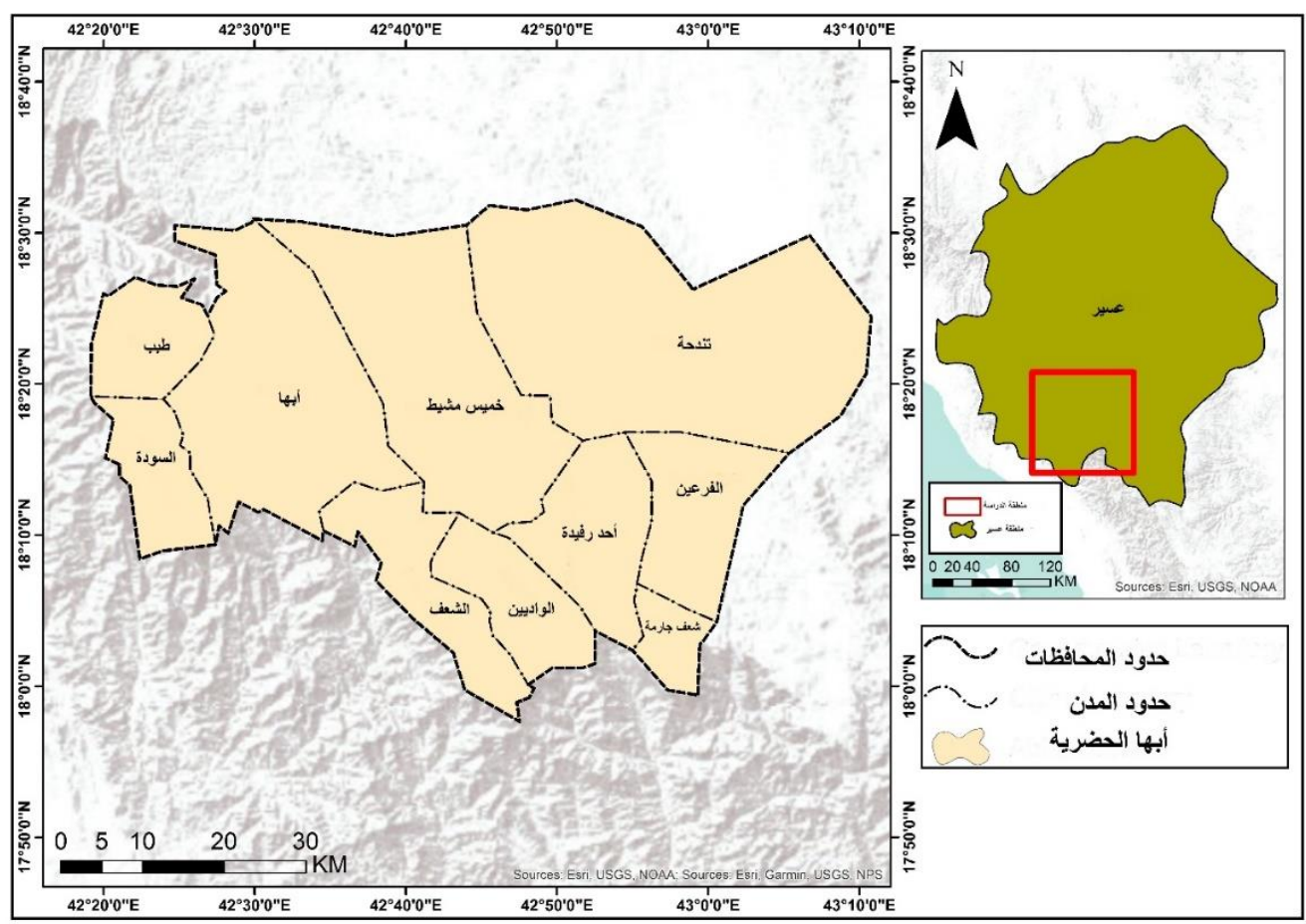

المصدر / من عمل الباحثتين بالاعتماد على نموذج الارتفاع الرقمي DEM بو اسطة برنامج (ArcGis10.3)

تضاريس منطقة أبها الحضرية تتميز بالتدرج من منسوب 1800 منر الى 2800 منر فوق سطح البحر وخاصا في الأجزاء الجنوبية الغربية من المنطقة حيث تتميز بالمنحدرات الثديدة وبصفة عامة تتميز بعض المناطق بسفوح شبه مستوية، ثم يلي ذلك منحدر ات عسير و التي تتميز بأنه يحدها شرقاسلسة جبال السروات وتمتن بمحاذاة السهول الساحلية وساحل البحر الأحمر، بطول 170 كم (وزارة الثئون البلدية والقروية وكالة الوزارة لتخطيط المدن ، 1997م: ص 26)، بينما يبلغ أقصى اتساع لها في أقصى الجنوب 150 كم تقريبا". كما توجد بعض المنحدرات الساحلية التي تخترقها بعض الأودية التي تتمبز بشدة الانحدار تجاه البحر الأحمر والانحدار التدريجي نحو الشرق. خريطة رقم (2). 
المجلة الدولية لنشر البحوث والدراسات

International Journal of Research and Studies Publishing

ISSN: 2709-7064
المجلد الثاني - الإصدار الثامن عشر

تأريخ الإصدار: 20 أبريل 2021م

\section{خريطة رقم (2) التضاريس في منطقة أبها الحضرية}

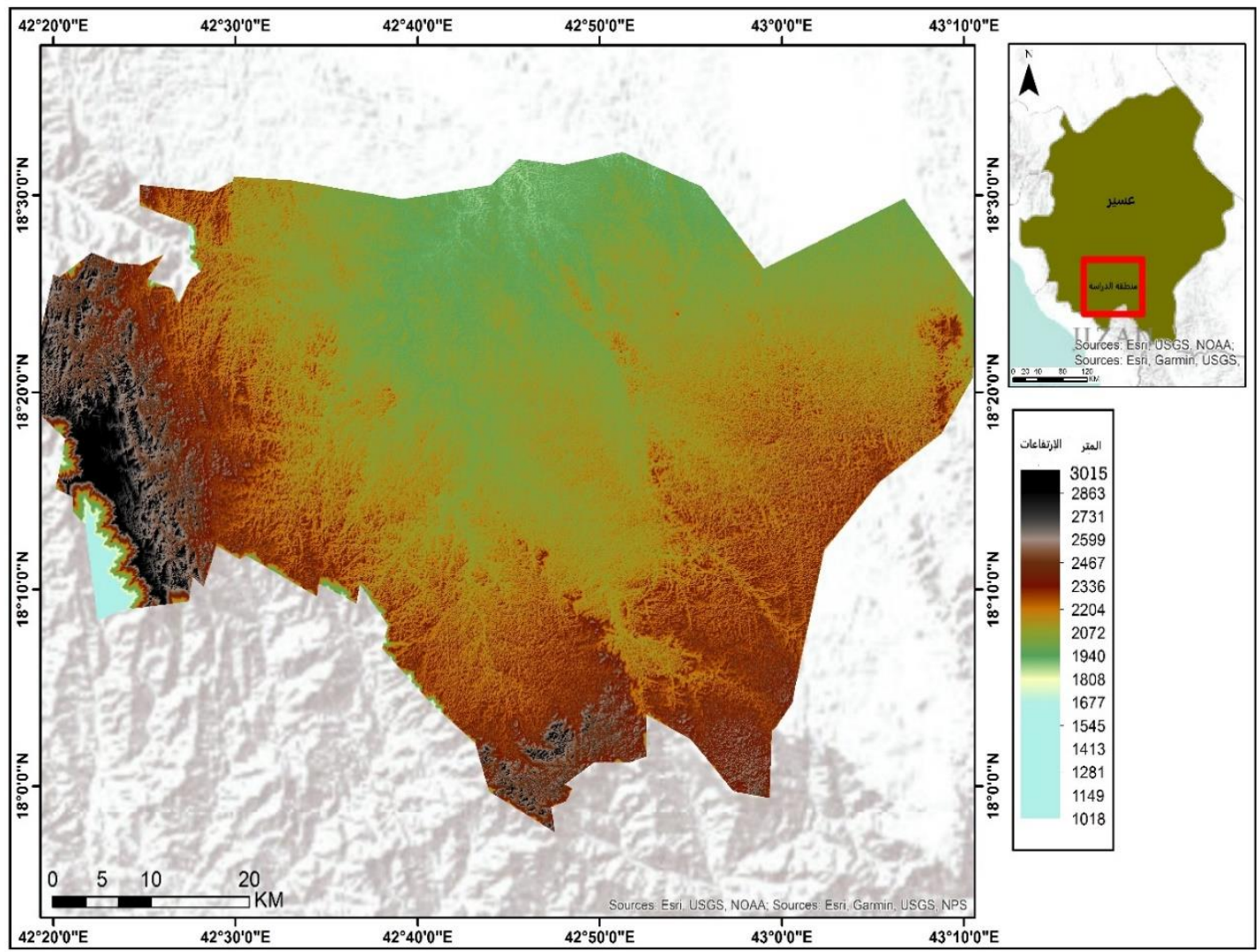

المصدر / من عمل الباحثنين بالاعتماد على نموذج الارتفاع الرقمي DEM بو اسطة برنامج (ArcGis10.3)

يتميز مناخ أبها الحضرية بصفة عامة بالاعتدال حيث توجد المرتفعات التي يزيد ارتفاعها عن 2000 منر حيث يتر اوح المتوسط السنوي للحر ارة من 12.3 × -12.6 م في محطات أبها وخميس مشيط على التو الي. وكانت اقل شهور العام حرارة هو شهر يناير حيث بلغ في أبها 9.9 oوفى خميس مشيط 10.1 ०بينما كانت اقصى متوسط للحر ارة في شهر أغسطس وبلغ 15.3 مفي أبهاو $15.5 \circ$ خميس مشيط. أما عن الرياح فتسود الرياح الجنوبية والجنوبية الغربية على مدينة أبها. وبشكل عام تتشط الرياح في أشهر ديسمبر ويناير وفبر اير ومارس حيث تصل متوسط سر عتها الى حو الي 7 و8 عقدة على التو الي في أبها وفى خميس مشيط تصل الى 6 و 7 من عقدة في نفس الثهور باتجاه الجنوب أما في فصل الصيف فتقل سر عة الرياح الى 5 و6 عقدة باتجاه الجنوب و الجنوب الغربي. بينما يرنبط هبوب الرياح على مدينة خميس مشيط بالتوزيع الفصلي لثهور السنة،

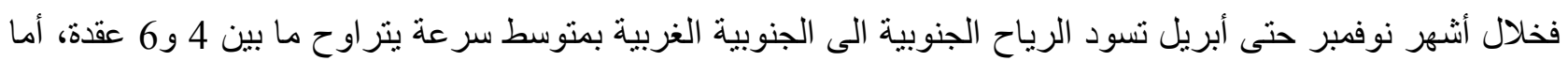
خلال أشهر الصيف فتكون الرياح شمالية شرقية بمتوسط سر عة 6 عقدة. 
المجلة الدولية لنشر البحوث والدراسات

International Journal of Research and Studies Publishing

ISSN: 2709-7064
المجلد الثاني - الإصدار الثامن عشر تأريخ الإصدار: 20 أبريل 2021م

وفي الصيف تتعرض هذه المناطق لهبوب التيار ات الحارة الجافة القادمة من صحر اء الربع الخالي محملة بذر ات الرمال ؛ مما تجعل الجو مكفهر ( حيدر ، 1978 ، ص21 ).تتركز الأمطار التي تسقط على غرب منطقة عسير خلال فصل الربيع حيث تحتل المرتبة الأولى في فصول السنة من حيث كمية الأمطار المنساقطة والتي تكون نتيجة عن التقاء الكتل الهوائية فوق البحر الأحمر ( الأحيدب ، 1995 ، ص 21 ) ، كما تسقط الأمطار على أبها الحضرية في فصل الثتاء نتيجة للرياح الخفيفة الباردة المحملة بالرطوبة والتي تهب من الناحية الجنوبية والجنوبية الغربية متأثره بالبحر الأحمر و المنحدرات الغربية .

\section{المؤشرات الايموغر افية للتنمية بمنطقة أبها الحضرية:}

الديمو غر افيا (Demography) أو علم السكان، هي عبارة عن در اسة لمجموعة من خصائص السكان، وهي الخصائص الكمية ومنها الكثافة السكانية، والتوزيع و النمو و الحجم بالإضافة الى الخصائص النوعية، ومنها العو امل الاجتماعية مثل التنمية و التعليم و التغذية و الثروة.

كما عرفت الأمم المتحدة عام 1958م الديمو غر افيا أنها علم يهدف الى دراسة المتمعات البشرية من حيث العدد و البنية و التطور و الخصائص العامة و الدر اسة الكمية.

المؤشر ات الديمو غر افية هي نظام للبيانات الإحصائية المستخدمة في تحليل العمليات في المجتمع. و على أساسها يمكن الوصول الى نتائج حول عدد وبنية السكان الذين يعيشون في منطقة معينة. فالمؤشر ات الديمو غر افية هي قيم مطلقة، و هذه القيم تساعد في تقدير التغيير ات في بنية السكان. ونتيح المؤشرات الديمو غر افية الرئيسية الوصول الى نتائج حول رفاهية المجتمع وصحته ونشاطه الاقتصادي.

فالمؤشر ات الديموغر افية لها دور كبير في نتكيل كثير من التحديات والفرص المعقدة التي تو اجهها المجتمعات، وتسهم در اسة المؤشر ات الديمو غر افية في فهم قضايا السكان و التنمية وبالتالي فهم العلاقات المتبادلة بين الظاهر ات السكانية و التنموية، وذللك من خلال تحديد وتحليل اثار المتغيرات السكانية والديمو غر افية على عملية التنمية، ويساهم ذلك في وضع الإطار المناسب للسياسة السكانية و التنموية في المجتمع.

وتتم در اسة المؤشر ات الديمو غر افية في منطقة أبها الحضرية من خلال در اسة المؤشرات السكانية التالية:

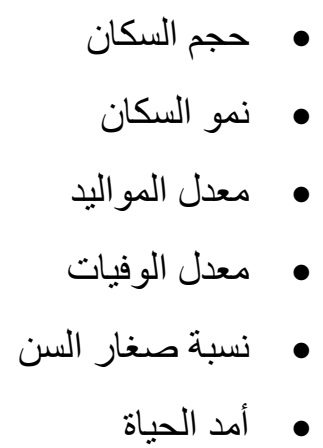


المجلة الدولية لنشر البحوث والدراسات

International Journal of Research and Studies Publishing
المجلد الثاني - الإصدار الثامن عشر تأريخ الإصدار: 20 أبريل 2021م

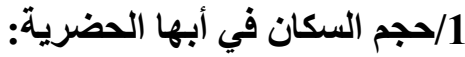

حجم السكان هو عدد السكان (الأفر اد) في مكان ووقت محدد. حيث يبلغ عدد سكان أبها الحضرية ( 778599 نسمة ) ، حسب إحصاءات عام 1435هـ يتوزعون على ثلاثة مدن هي أبها ويبلغ عدد سكانها ( 254.290 نسمة) ، ويمثلون 36\% من سكان المنطقة ، ومدينة خميس مشيط ويبلغ عدد سكانها(463.26 نسمة) ويشكلون 59.5\% من سكان المنطقة ، ومدينة احد رفيدة ويبلغ عدد سكانها ( 6.983 نسمة ) ويمثلون 7.9\% من سكان المنطقة ، جدول رقم (1) و الثكل رقم (1).مما يعني ان اكثر من نصف سكان أبها الحضرية يتركزون في

خميس مشيط، تليها أبها و اقلهم احد رفيدة من حيث عدد السكان. (الرؤية العمر انية الثاملة لحاضرة ابها، 1440ه، ص52). ويلاحظ على سكان منطقة أبها الحضرية ارتفاع نسبة الذكور عن نسبة الإناث بنسبة بلغت 57.1\% من السكان للذكور، 42.9 من السكان للإناث. شكل رقم (2).

جدول رقم (1) توزيع السكان على مدن منطقة أبها الحضرية

\begin{tabular}{|c|c|c|c|}
\hline نسبة الاناث & نسبة الأكور & عدد السكان & المحافظة \\
\hline$\% 43.0$ & $\% 57.0$ & 463326 & خميس مشيط \\
\hline$\% 42.4$ & $\% 57.6$ & 254290 & مدينة أبها \\
\hline$\% 44.9$ & $\% 55.1$ & 60983 & احد رفيدة \\
\hline$\% 42.9$ & $\% 57.1$ & 778599 & المجموع \\
\hline
\end{tabular}

المصدر: من عمل الباحثثين اعتمادا على بيانات المرصد الحضري لابها الحضرية 1435هـ و الرؤية العمر انية الثناملة

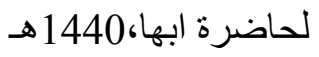

شكل رقم (1) عدد السكان في مدن أبها الحضرية

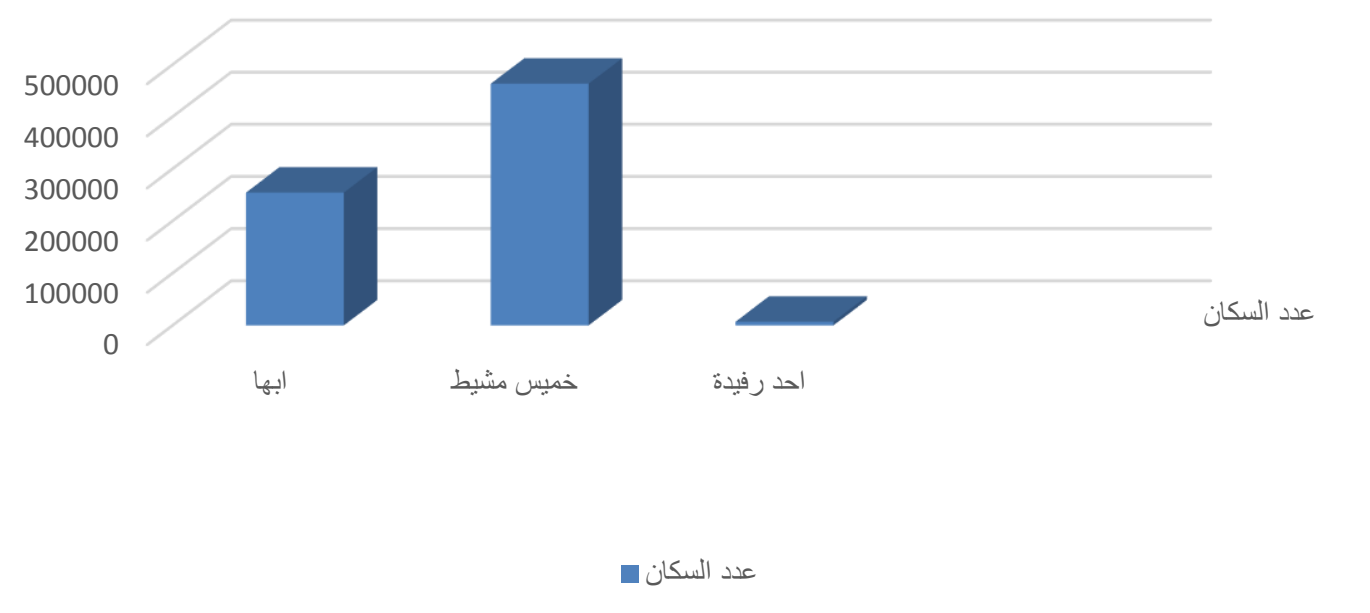


المجلة الدولية لنشر البحوث والدراسات

International Journal of Research and Studies Publishing

ISSN: 2709-7064
| المجلد الثاني - الإصدار الثامن عشر تأريخ الإصدار: 20 ت 20 أبريل 2021م

المصدر / من عمل الباحثتين اعتمادا على بيانات مؤشرات المرصد الحضري لابها الحضرية ومدن منطقة عسبر (التقرير الثامل 1435ه)؛

\section{شكل رقم (2) نسبة الذكور الى الاناث في منطقة أبها الحضرية}

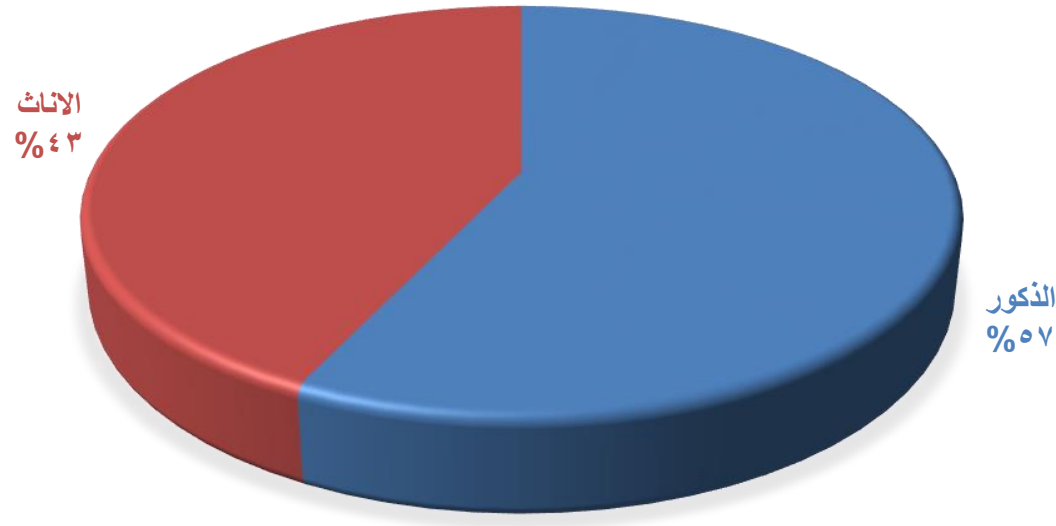

المصدر / من عمل الباحثتين اعتمادا على بيانات مؤشر ات المرصد الحضري لابها الحضرية ومدن منطقة عسير (التقرير الثامل 1435ه)،

\section{2/ نمو السكان في منطقة أبها الحضرية:}

نمو السكان يقصد به اختلاف في حجم السكان في المجتمع، كما هو تز ايد عدد السكان بشكل منصاعد خلال فترة زمنية معينة. (الجيلي ،1984م، ص1964). ويمثل زيادة عدد السكان في منطقة معينة. وله مجموعة من التأثثرات أهمها الضغط على الموارد

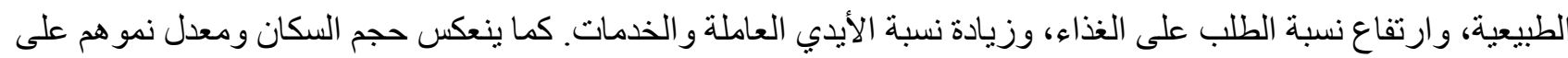
عدد من القوى الأساسية المتمنلة في معدلات الوفيات و الخصوبة و الهجرة الدولية. وبتتبع نمو السكان في منطقة أبها الحضرية نجد إن معدل نمو السكان بها بلغ 2.4\% سنويا في عام 1435هـ لينخفض الى 2.

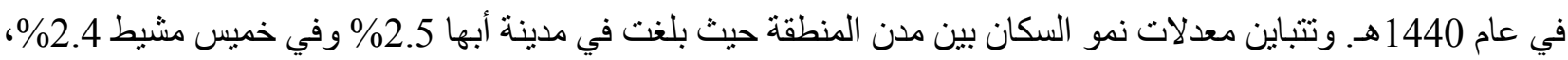
وبلغت في أحد رفيدة 2.2\%. (مؤشرات المرصد الحضري لأبها الحضرية ومدن منطقة عسير ،1435 هـ،صو96)، ونلاحظ إن نسبة نمو السكان في مدن منطقة أبها الحضرية متقاربة، ومنخفضة، حيث تتمثل محددات نمو السكان في: المواليد و الوفيات 
المجلة الدولية لنشر البحوث والدراسات

International Journal of Research and Studies Publishing
المجلد الثاني - الإصدار الثامن عشر تأريخ الإصدار: 20 أبريل 2021م

أثر النمو السكاني على مخططات التنمية:

تختلف وجهات نظر الديموغر افيين و الاقتصاديين حول اثر النمو السكاني على التنمية ، حيث يري بعضهم إن للنمو السكاني

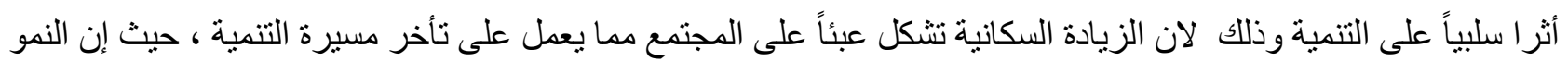

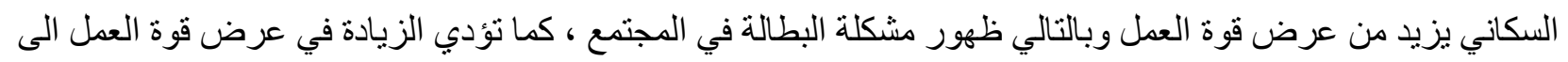
خفض الأجور ، وبالتالي قلة الدخل مما يؤثر على قدرة الأسر على الوفاء باحتياجات أفر ادها من غذاء وتعليم وتدريب، مما يؤدي الى زيادة في أعداد العمال غير المؤهلين و المدربين في سوق العمل ـ كما إن التدريب و التأهيل للأفر اد يساهم في عملية التنمية، إلا إن النمو المنز ايد للسكان يؤخر عملية التنمية. كما ان النمو السكاني المنز ايد يؤدي الى زيادة الطلب على السلع الاستهلاكية و الضغط على قطاع الخدمات، مما يعيق مسيرة التنمية. وبعضهم الأخر يري أن للنمو السكاني أثر ا إيجابيا على التنمية في المجتمع، ويشكل دافع للتنمية، حيث أن النمو السكاني يزيد من نسبة الثباب في المجتمع أي (قوى العمل)، أي زيادة القوة العاملة في المجتمع (الفئة المنتجة) الى إجمالي السكان، مما بعني

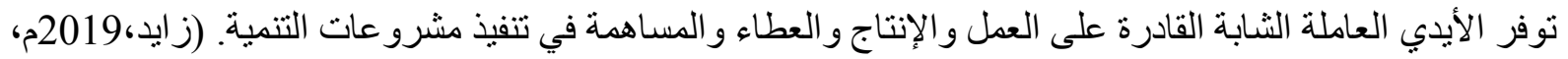

ص535).

\section{3/ معدل المواليد(الخصوية)}

تعتبر المو اليد اهم محددات النمو السكاني، ويتم تعريف معدل الخصوبة بانها نسبة إجمالي عدد المو اليد لفترة معينة (كل عام)

من الأطفال الى إجمالي السكان لكل ألف شخص. فهو يسهم في نمو وزيادة حجم السكان او ثباته، وتحديد نوعه ومعدلاتها تنقاوت من مجتمع الى أخر.

بلغ المعدل الخام للمو اليد في أبها الحضرية 20.8مولود لكل ألف نسمة، وينباين هذا المعدل في مدن المنطقة حيث منلت مدينة أبها اعلى معدل للمو اليد بلغ 33.8مولود لكل ألف نسمة، تليها خميس مشيط 15.1 مولود لكل ألف نسمة، واحد رفيدة 9.6مولود

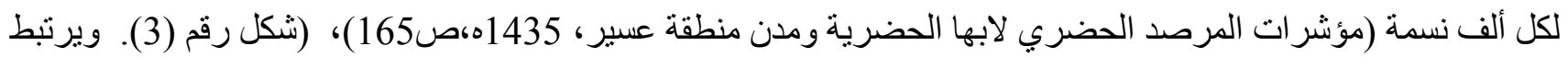
مفهوم المو اليد بالخصوبة باعتبار ها تشير الى المعدل الفعلي للمو البد، كما تشير الى القدرة على الإنجاب. حيث بلغ مدل لهدير

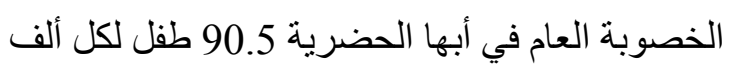
سيدة، ويتباين هذا المعدل بين مدن المنطقة حيث بلغ 133.3طفل لكل ألف سيدة في مدينة أبها، 69.3طفل لكل ألف سيدة في خميس مشيط، 43.6طفل لكل ألف سيدة في أحد رفيدة. (مؤشرات المرصد الحضري لابها الحضرية ومدن منطقة عسير ،(82) 1435، 
المجلة الدولية لنشر البحوث والدراسات

International Journal of Research and Studies Publishing

ISSN: 2709-7064
| المجلد الثاني - الإصدار الثامن عشر

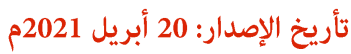

\section{شكل رقم (3) معدل المواليد الخام في مدن منطقة أبها الحضرية}

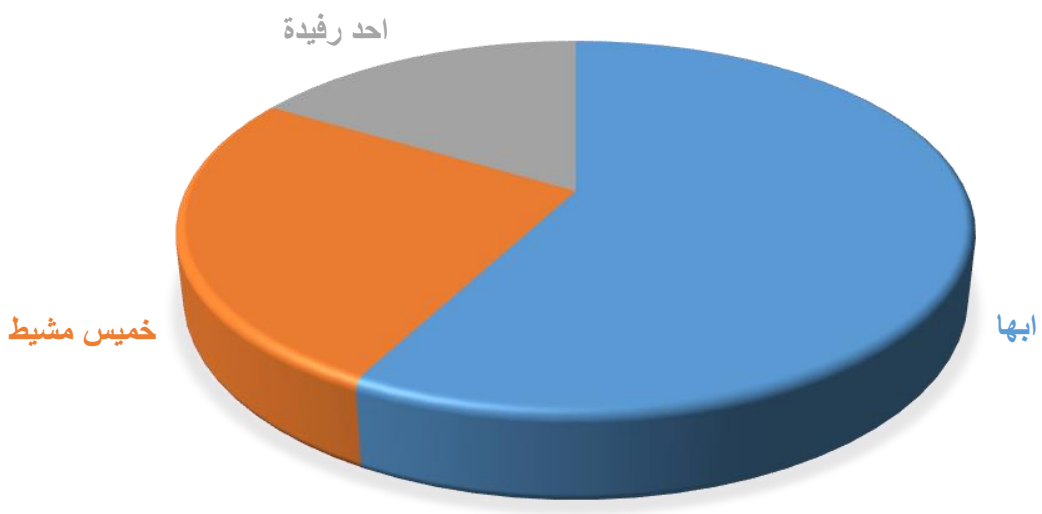

المصدر / من عمل الباحثتين اعتمادا على بيانات مؤشر ات المرصد الحضري لابها الحضرية ومدن منطقة عسير (التقرير الثامل 1435ه)؛

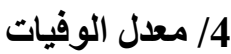

تعتبر الوفيات من العو امل الحيوية للسكان، وينم حساب معدل الوفيات بقسمة إجمالي عدد الوفيات في السنة على إجمالي عدد السكان لكل ألف شخص. حيث إنها تؤثر على حجم السكان وتركيبهم، كما إنها تعمل على إنقاص عدد الأفر اد. تختلف معدلات الوفيات من مجتمع الى أخر ومن فترة زمنية الى أخرى في المجتمع نفسه، بالإضافة الى الأسباب الطبيعية التي تحدث بسبب الحو ادث و الجر ائم و الحروب و غيره. (كرداشة، 2010م، ص1430). و اهتمت الأمم المتحدة بتقليل عدد الوفيات بين الأطفال

$$
\text { و أدرجته الهدف الرابع من أهداف الألفية لعام (2000-2015م.). }
$$

بلغ عدد وفيات الأطفال في منطقة أبها الحضرية 15.6 حالة وفاة لكل ألف طفل. حيث بلغت وفيات الأطفال الرضع (اقل من سنة) 6.7 حالة وفاة لكل ألف طفل، تتباين بين مدن المنطقة، حيث بلغت 10.8 حالة وفاة لكل ألف طفل في مدينة أبها، وفي مدينة خميس مشيط بلغت 1.9حالة وفاة لكل ألف طفل، و 5.1 حالة وفاه لكل ألف طفل بمدينة احد رفيدة. (شكل رقم 4) . بينما بلغت وفيات الأطفال دون سن الخامسة 8.9 حالة وفاة لكل ألف طفل. (مؤشر ات المرصد الحضري لابها الحضرية ومدن

منطقة عسير ،1435هـ،ص150)، و وتتباين هذه النسبة بين مدن منطقة أبها الحضرية حسب الثنكل رقم(5). حيث بلغت 13.6حالة وفاه لكل ألف طفل في مدينة أبها، و2.9 حالة وفاه لكل ألف طفل في مدينة خمبس مشيط، 10.2حالة وفاة لكل ألف طفل في مدينة أحد رفيدة. ويلاحظ ارتفاع هذه النسبة في مدينة أبها عن بقية مدن منطقة أبها الحضرية. و انخفاضها في مدينة خميس مشيط بالر غم من ارتفاع عدد السكان بها. 
المجلة الدولية لنشر البحوث والدراسات

International Journal of Research and Studies Publishing

ISSN: 2709-7064
| المجلد الثاني - الإصدار الثامن عشر تأريخ الإصدار: 20 أبريل 2021م

شكل (4): معدل وفيات الرضع اقل من سنة في مدن منطقة أبها الحضرية

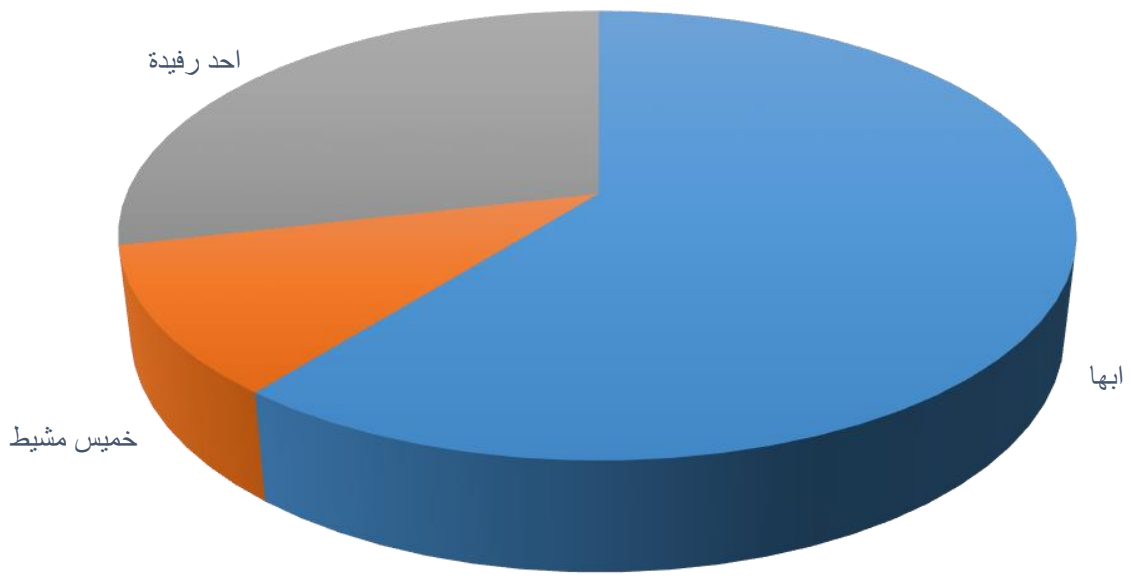

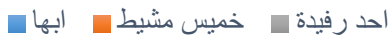

المصدر / من عمل الباحثتين اعتمادا على بيانات مؤشرات المرصد الحضري لابها الحضرية ومدن منطقة عسير (التقرير

الثامل 1435ه) (20) (1435)

شكل (5) معدل وفيات الأطفال دون الخامسة في مدن منطقة أبها الحضرية

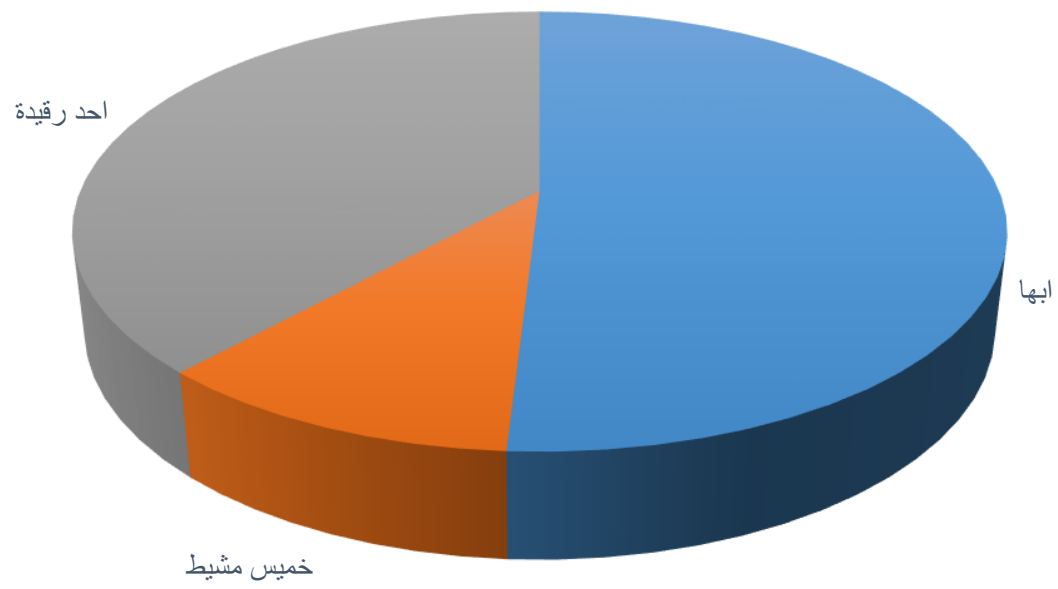

|حد رقيدة ت خميس مشيط | ابهاص

المصدر / من عمل الباحثثين اعتمادا على بيانات مؤشر ات المرصد الحضري لابها الحضرية ومدن منطقة عسير (التقرير

الثامل 1435ه) 
المجلة الدولية لنشر البحوث والدراسات

International Journal of Research and Studies Publishing

ISSN: 2709-7064
المجلد الثاني - الإصدار الثامن عشر تأريخ الإصدار: 20 أبريل 2021م

ويعتبر معدل وفيات الرضع أحد المؤشرات التي يحكم بها على تحسن الخدمات الصحية، (عانشور،2015م، ص 142) وهي تعكس مر احل التنمبة التي مرت بها المنطقة، والتي توضح مدى الاهتمام و العناية بالمولود قبل ولادته وخلال السنة الأولى من عمره. ويتضح ذللك من خلال الاهتمام بالخدمات الصحية بالمنطقة، حيث بلغ عدد المستشفيات المخصصة للأطفال 80\% من جملة المستشفيات في منطقة أبها الحضرية، مما انعكس إيجابيا على خفض معدل وفيات الأطفال. تتباين المستشفيات الصحية المخصصة للأطفال من مدينة لأخري، حيث بلغ توفر المستشفيات الخاصة بالأطفال 85.7\% من جملة المستشفيات في مدينة أبها، وبلغت 71.4\% من جملة المستشفيات في مدينة خميس مشيط، وبلغت نسبة 100\% من جملة المستشفيات في مدينة أحد

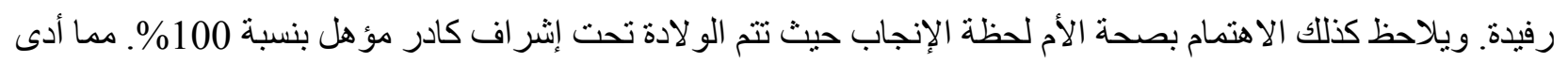

ذلك الى خفض نسبة وفيات الأمهات في المنطقة، حيث بلغت 18.6(حالة وفاة أم لكل مائة الف مولود حي)، ((مؤشرات المرصد الحضري لابها الحضرية ومدن منطقة عسير ،1435هـص161) ،وهذا يعكس تطور الوضع الصحي في منطقة أبها الحضرية.

4/ تسبة صغار السن:

صغار السن هم الأطفال الأقل من عمر 15 سنة، وهي فئة غير منتجة (معالة). ارتفاع نسبة صغار السن تعني ارتفاع نسبة الإعالة، و ارتفاع الإنفاق لسد احتياجاتهم من غذاء وملبس وتعليم ور عاية صحية، و هذا ينعكس على الجهود المبذولة لإحداث

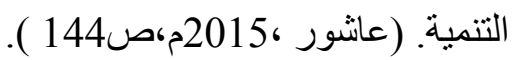

بلغت نسبة صغار السن في أبها الحضرية 35.7\%، من جملة السكان في المنطقة، أي ما يزيد عن ثلث السكان. و وتتباين هذه النسبة بين مدنها، حيث بلغت في أبها 930.9\% وفي خميس مشيط بلغت نسبة صغار السن 37.6\%، وفي أحد رفيدة بلغت 40.9\%. (مؤشر ات المرصد الحضري لابها الحضرية ، 1435 هـ ،ص27) ، و وتصنيف فئة صغار السن الى فئتين هما : الفئة الأقل من خمسة سنوات ، و الفئة من (5سنة الى 14 سنة) كما يبين ذلك الجدول رقم ( 2 ) و (الثكل رقم 6). ويلاحظ ارتفاع نسبة الأطفال في السن ما بين (5 سنوات الى 14 سنة) في مدينة خميس مشيط ومدينة احد رفيدة، بل في منطقة أبها الحضرية، مما يعني هناك فئة كبيرة من صغار السن سوف تصل في وقت قريب الى فئة الإنتاج و العمل مما يساهم في نوفير الايدي العاملة التي تساهم بدور ها في المشاركة في تنفيذ مشرو عات التتمية الاقتصادية في المنطقة. جدول رقم (2) توزيع فئات صغار السن في مدن منطقة أبها الحضرية

\begin{tabular}{|c|c|c|}
\hline \multicolumn{2}{|c|}{ توزيع السكان حسب العمر } & \multirow{2}{*}{ المدينة } \\
\hline من 5 -14 سنوات & اقّل من 5 سنوات & \\
\hline$\% 9.8$ & $\% 21.1$ & أبها \\
\hline$\% 25.6$ & $\% 12.0$ & خميس مشيط \\
\hline$\% 27.5$ & $\% 13.4$ & احد رفيدة \\
\hline$\% 27.5$ & $\% 15.1$ & أبها الحضرية \\
\hline
\end{tabular}

المصدر / من عمل الباحثتين اعتمادا على بيانات مؤشرات المرصد الحضري لابها الحضرية ومدن منطقة عسير (التقرير

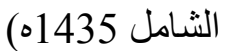


المجلة الدولية لنشر البحوث والدراسات

International Journal of Research and Studies Publishing

ISSN: 2709-7064
المجلد الثاني - الإصدار الثامن عشر تأريخ الإصدار: 20 أبريل 2021م

\section{شكل (6) توزيع السكان حسب فئات السن في مدن منطقة أبها الحضرية}

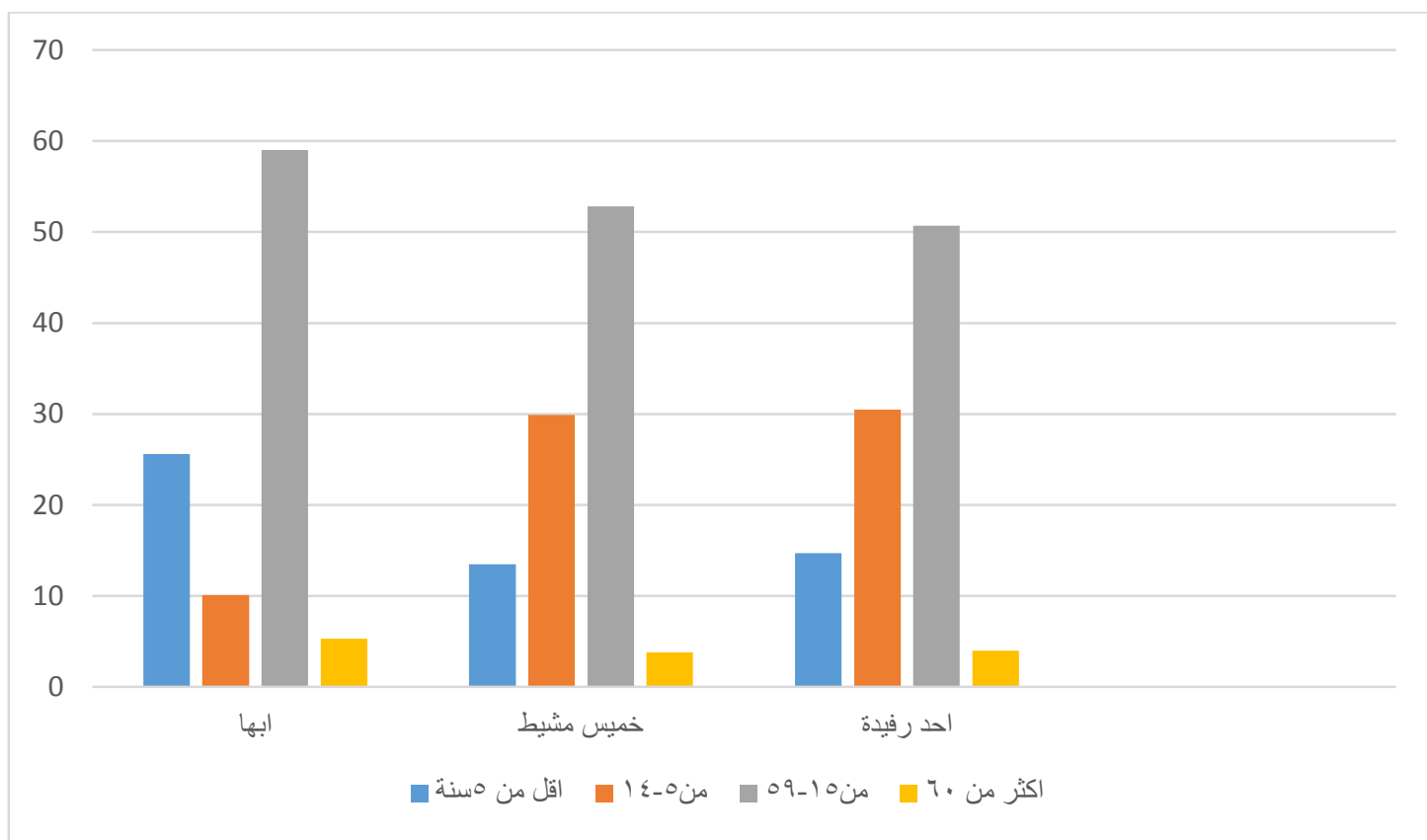

المصدر / من عمل الباحثثين اعتمادا على بيانات مؤشرات المرصد الحضري لابها الحضرية ومدن منطقة عسير (التقرير الثنامل 1435ه)، 6

يقصد بأمد الحياة (توقعات الحياة عند الميلاد) (عاشور 2015م، ص1481)، و هي تعكس مجمل الأوضاع المعيشية والصحية للسكان، حيث يرتبط مستوى المعيثة بمستوى الاخل والذي بدوره يؤثر على نوعية الغذاء و التي تؤثر صحة الفرد ومقدرته على العمل و الإنتاج.

بلغ منوسط امد الحياة في منطقة أبها الحضرية 74.0س سنة، ويتفاوت منوسط امد الحياة في المنطقة بين الذكور والإناث، حيث بلغ منوسطة عند الذكور 72.8 سنة ،بينما بلغ منوسط امد الحياة عن الاناث 75.2سنة. (مؤشرات المرصد الحضري لابها

الحضرية ومدن منطقة عسير 1435هـ،ص151)، ويلاحظ ارتفاع امد الحياة عند الاناث اكثر من الذكور شكل رقم (7)، ويرجع السبب في ذلك الى تعرض الذكور الى مخاطر المهنة ، والحركة من اجل العمل ، على عكس الإناث فهن اقل عرضة

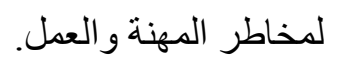


المجلة الدولية لنشر البحوث والدراسات

International Journal of Research and Studies Publishing

ISSN: 2709-7064
المجلد الثاني - الإصدار الثامن عشر تأريخ الإصدار: 20 20 أبريل 2021م

شكل رقم (7) العمر المتوقع عند الميلاد للأكور والإناث بالسنوات في أبها الحضرية

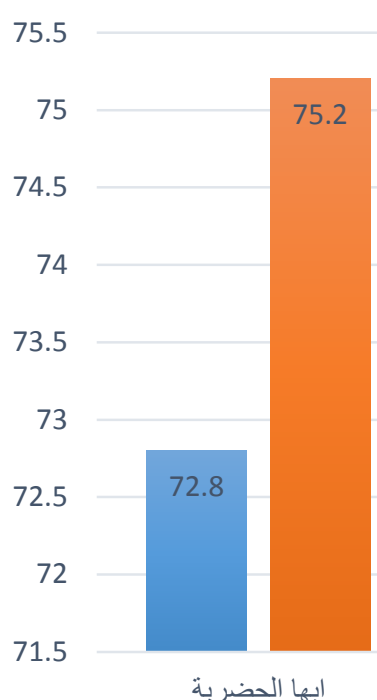

ص الاناث ص الذكور

المصدر / من عمل الباحثثين اعتمادا على بيانات مؤشرات المرصد الحضري لابها الحضرية ومدن منطقة عسير (التقرير الثامل 1435ه)

الخاتمة:

نالت در اسة القضايا السكانية اهتمام عالمي خاصة من قبل الأمم المتحدة، مما أدى الى ظهور العديد من الدر اسات السكانية التي

وجهت اهتمامها لمناقثنة الكثير من القضايا المتعلقة بالجو انب الديموغر افية والاقتصادية و الاجتماعية. وتلعب المؤشرات الديمو غر افية دور اهاما في التنمية. ويلاحظ على منطقة أبها الحضرية نمو معتدل في السكان ينوازن مع المشروعات التنموية ويتو افق مع الخدمات المقدمة للسكان، ويظهر ذللك بوضوح في انخفاض معدل وفيات الأطفال نتيجة للتحسين الكبير في الخدمات الصحية المقدمة لهم من قبل و لادة الطفل وحتى السنين الأولى من عمره. كذلك يلاحظ انخفاض في نسبة المو اليد و انخفاض نسبة صغار السن، ويعكس ذلك درجة الوعي لاي السكان. وكل ذلك يوضح تطور مستويات التنمية التي حظيت بها منطقة أبها الحضرية.

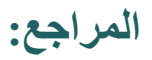

1/ الأحيدب: إبر اهيم سليمان ( 1995م ) المدخل إلى الطقس و المناخ و الجغر افيا المناخية ، الرياض ، جامعة الأمام محمد بن سعود. 
المجلة الدولية لنشر البحوث والدراسات

International Journal of Research and Studies Publishing

ISSN: 2709-7064
المجلد الثاني - الإصدار الثامن عشر

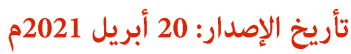

2/ الجيلي: علي عبد الرزاق (1984 م)، علم اجتماع السكان، دار المعرفة الجامعية، القاهرة.

3/ بلوم: ديفيد (2020م)، السكان في عام 2020م العو امل الديمو غر افية يمكن ان تكون محركاً قوياً لعملية التنمية الاقتصادية ووتيرتها، التمويل و التنمية، مارس 2020م.

4/ حيدر: أحمد محمد ( 1978م) الجغر افيا الزر اعية لمنطقة عسير، أبها ، مطبو عات نادي أبها الأدبي. 5/ زايد: ريم (2019م)، السكان و التنمية (مفاهيم وأسس نظرية)، مجلة العلوم الإنسانية، عدد 52 ، مجلد ب. جامعة الاخوة منتوري، قسنطينة ، الجزائر 6/ كر ادشة: منبر عبد الله (2010م ) ، علم السكان، عالم الكتب الحديث.. 7/ عاثور : اشرف محمد (2015م) ، جغر افية التنمية في عالم متغير ،دار المعرفة الجامعية ، الإسكندرية. مصر. التقاريز والمواقع الاككترونية:

1/ مؤشر ات المرصد الحضري لابها الحضرية ومدن منطقة عسير (التقرير الثشامل 1434-1435ه) 2/ برنامج مستقبل المدن السعودية ـالرؤية العمر انية الثاملة لحاضرة أبها، وزارة الثؤون البلدية والقروية 1440 هـ، الرياض 3/ وزارة الثئون البلدية والقروية وكالة الوزارة لتخطيط المدن ، 1997م. 5 5 موقع وزارة الصحة على شبكة الانترنت. DOI: doi.org/10.52133/ijrsp.v2.18.2 